\title{
Comparison of Two Enzyme Immunoassays and Four Lysate Antigens for the Detection of Antibody in Canine Blastomycosis
}

\author{
Matthew Day, Arin Esterbrook, Ignatius Bisharat, Abdullah Saleh Albqomi, Bryn Kennell, \\ Russ Manteca, Heaton Oakes, Geoffrey M. Scalarone, Gene M. Scalarone*
}

Department of Biological Sciences, Idaho State University, Pocatello, USA

Email: genescalarone@isu.edu

How to cite this paper: Day, M., Esterbrook, A., Bisharat, I., Albqomi, A.S., Kennell, B., Manteca, R., Oakes, H., Scalarone, G.M. and Scalarone, G.M. (2021) Comparison of Two Enzyme Immunoassays and Four Lysate Antigens for the Detection of Antibody in Canine Blastomycosis. Open Journal of Veterinary Medicine, 11, 136-142. https://doi.org/10.4236/ojvm.2021.114009

Received: March 26, 2021

Accepted: April 25, 2021

Published: April 28, 2021

Copyright $\odot 2021$ by author(s) and Scientific Research Publishing Inc. This work is licensed under the Creative Commons Attribution International License (CC BY 4.0).

http://creativecommons.org/licenses/by/4.0/

\begin{abstract}
Blastomycosis, the systemic fungal disease of humans and animals caused by Blastomyces dermatitidis and the cryptic species Blastomyces gilchristii, is often misdiagnosed as a bacterial or viral pulmonary disease. Therefore, the development of improved immunodiagnostic assays for this disease has been the primary focus of research in our laboratory. The present study was designed to evaluate four Blastomyces yeast-phase lysate antigenic preparations (human, 597, Eagle River, WI; dog, ERC-2, WI; Human, B5927, Mountain Iron, MN; soil, 85, Georgia, ATCC 56920) for their ability to detect antibody in 48 serum specimens from dogs with diagnosed blastomycosis using an indirect ELISA (STD) compared to a biotin-streptavidin ELISA (B-SA). All four lysate antigens were able to detect antibodies in the specimens with mean absorbance values ranging from 0.930 (B5927) to 1.142 (ERC-2) with the STD ELSA and from 1.395 (B5927) to 1.775 (85) with the B-SA ELISA. The results indicated that both ELISA methods could be utilized for antibody detection, but the B-SA ELISA exhibited greater sensitivity than the STD ELISA with all four of the lysates.
\end{abstract}

\section{Keywords}

Blastomyces lysate Antigens, Antibody Detection, ELISA Methods, Canine Blastomycosis, Blastomyces dermatitidis, Blastomyces gilchristii

\section{Introduction}

Blastomyces dermatitidis and a recently described cryptic species, Blastomyces gilchristii, are thermally dimorphic fungal organisms and the causative agents of blastomycosis in humans and animals. Blastomyces is endemic in the Southeas- 
tern and Upper Midwestern regions of the US, including highly endemic areas in Wisconsin and Minnesota, and in joining regions of Canada. The fungus is found primarily in areas of moist soil and decaying matter. The organism exists in the mycelial phase in nature and the disease is acquired by the inhalation of the mycelial spores into the lungs where they convert to broad-based yeast cells at body temperature. Primary pulmonary infection may ensue or the organism may disseminate to other organs including the central nervous system with possible meningeal involvement [1] [2] [3] [4].

Blastomycosis is difficult to diagnose in a clinical environment and is often misdiagnosed as a bacterial or viral disease. It may be fatal if proper diagnosis and treatment are not initiated especially in immunocompromised individuals. Culturing and histologic techniques are effective, but in some instances may not provide a suitable diagnosis and may delay treatment. Due to time constrictions, the fungus is often difficult to culture. A more immediate diagnosis (before dissemination) can lead to better patient outcomes due to more timely administration of treatment.

Therefore, more investigators have begun to concentrate on using new immunodiagnostic methods in an effort to improve the laboratory diagnostic detection of antigens or antibodies in humans and animals [5]-[14].

The focus of research in our laboratory has been on comparative studies to improve the diagnosis of blastomycosis. We have prepared novel Blastomyces yeast phase lysate antigens from human, animal, and environmental isolates of the fungus and conducted numerous studies on the use of such antigenic preparations for the detection of antibodies in serum specimens of immunized and infected animals. These lysate preparations have also been used to immunize rabbits and the sera used in antigen detection assays [15]-[21]. The studies have provided encouraging results with regard to continued evaluation of the lysate antigens as immunodiagnostic reagents for the improved diagnosis of blastomycosis.

The aim of this present study was to evaluate four yeast lysate preparations from human, animal, or environmental isolates of the fungus with regard to antibody detection in serum specimens from dogs with diagnosed blastomycosis using two different enzyme-linked immunoassays (an indirect ELISA compared to a biotin-streptavidin ELISA).

\section{Materials and Methods}

\subsection{Lysate Antigens}

Three yeast phase lysate antigens were prepared from human (597, Eagle River, Wisconsin), human (B5927, Mountain Iron, Minnesota) and soil (85, Georgia, ATCC 56920) isolates of $B$. dermatitidis and from one isolate of $B$. gilchristii (dog, Wisconsin, ERC-2) [22]. Each of the antigens was prepared by a method similar to one previously used for the production of yeast phase lysate antigen from Histoplasma capsulatum [23] [24] [25] and modified in our laboratory for 
the production of $B$. dermatitidis lysate antigen [15]. Yeast cells were grown for 7 days at $37^{\circ} \mathrm{C}$ with shaking in a chemically defined medium, harvested by centrifugation $(700 \times \mathrm{g}, 5 \mathrm{~min})$, followed by rinsing with sterile distilled water, resuspended in distilled water and allowed to lyse for 7 days at $37^{\circ} \mathrm{C}$ with shaking. The preparations were centrifuged, as above, filter sterilized ( $0.2 \mathrm{um}$ filter) and merthiolate $(1: 10,000)$ added as a preservative and protein determinations were performed on the lysates using the BCA Protein Assay (Pierce Chemical Company, Rockford, IL). Dilutions of the antigenic preparations used in the assays were based on protein concentration.

\subsection{Serum Specimens}

Forty-eight serum specimens from dogs with diagnosed blastomycosis (histopathology or culture) were provided by Dr. A.M. Legendre (University of Tennessee College of Veterinary Medicine, Knoxville, Tennessee).

\subsection{Standard (STD) Indirect ELISA}

The ability of each of the four lysate antigens to detect antibodies in the above serum specimens was determined using the standard (STD) indirect ELISA as previously described [15]-[22]. Each lysate antigen was diluted (2000 ng/ml of protein) in a carbonate-bicarbonate coating buffer ( $\mathrm{pH} 9.6)$ and then added to triplicate wells (100 ul) of a NUNC 96-well microplate (Fisher-Thermo). The plates were incubated overnight at $4 \mathrm{C}$ in a humid chamber followed by washing $3 \mathrm{x}$ with phosphate buffered saline containing $0.15 \%$ Tween 20 (PBS-T). The dog serum specimens (1:2000 dilution, $100 \mathrm{ul})$ were added to the microplate wells in triplicate and incubated for $30 \mathrm{~min}$ at $37^{\circ} \mathrm{C}$ in a humid chamber. Following incubation, the wells were washed as above and $100 \mathrm{ul}$ of goat anti-dog $\operatorname{IgG}(\mathrm{H} \&$ L) peroxidase conjugate (Kirkegaard \& Perry, Gaithersburg, MD, KPL) was added to each well and incubated for $30 \mathrm{~min}$ at $37^{\circ} \mathrm{C}$. The plates were again washed as above and $100 \mathrm{ul}$ of SureBlue Reserve TMB peroxidase substrate (KPL) was added to each well and incubated for approximately $3 \mathrm{~min}$ at room temperature. The reaction was stopped by the addition of Stop Solution (KPL) and the absorbance read at 450 using a Bio-Tek Synergy HT reader (Winooski, VT).

\subsection{Biotin-Streptavidin (B-SA) ELISA}

The ability of each of the four lysate antigens to detect antibodies in the above serum specimens was also determined using the biotin-streptavidin (B-SA) ELISA as previously described [17]. As above in the STD ELISA the plates were incubated, washed, the dog sera added and incubated. Following incubation 100 ul of goat anti-dog $\operatorname{IgG}(\mathrm{H} \& \mathrm{~L})$ biotin labeled antibody (1:2000, KPL) was added to each well and incubated at $37^{\circ} \mathrm{C}$ for $30 \mathrm{~min}$. The plates were again washed as above and $100 \mathrm{ul}$ of peroxidase labeled streptavidin (1:400, KPL) was added to each well, incubated at $37^{\circ} \mathrm{C}$ for $30 \mathrm{~min}$, plates washed, substrate added (KPL), incubated for approximately 3 minutes, stop solution added and absorbance read. 


\section{Results}

Both ELISA methods were very efficient with regard to the detection of antibodies in the dog serum specimens, but the BS-A method produced mean absorbance values considerably greater than the STD assay in all instances. A mean absorbance value of 4.197 was obtained with the four antigens in the STD assay compared to a mean absorbance value of 5.971 with the BS-A assay, an increase of 1.774 (mean absorbance value, sensitivity increase) over the STD assay. The results obtained with each assay are as follows.

\subsection{STD Indirect ELISA}

The antibody detection with this method indicated that the ERC-2 antigen exhibited the greatest mean absorbance value (1.142, SD 0.063$)$ of the four antigens (Figure 1). The other three antigens, 85, 597 and 5927 detected antibodies in the dog sera with mean absorbance values of 1.123 (SD 0.076), 1.002 (SD 0.071) and 0.930 (SD 0.041) respectively.

\subsection{BS-A ELISA}

Antibody detection results with the four lysate antigens with the dog sera are shown in Figure 2. The soil antigen (85) exhibited the greatest absorbance value of 1.775 (SD 0.097) followed by ERC-2, B5927 and 597 with mean absorbance values of $1.649(0.078), 1.395(0.049)$ and 1.152 (0.052) respectively.

\section{Discussion and Conclusion}

For many years our laboratory has been involved in the production and evaluation of Blastomyces yeast phase lysate antigens produced from human, animal and environmental isolates of the fungus. Most of our studies have been involved with using these antigens for ELISA antibody detection in serum specimens from dogs and humans with blastomycosis or from rabbits immunized

2

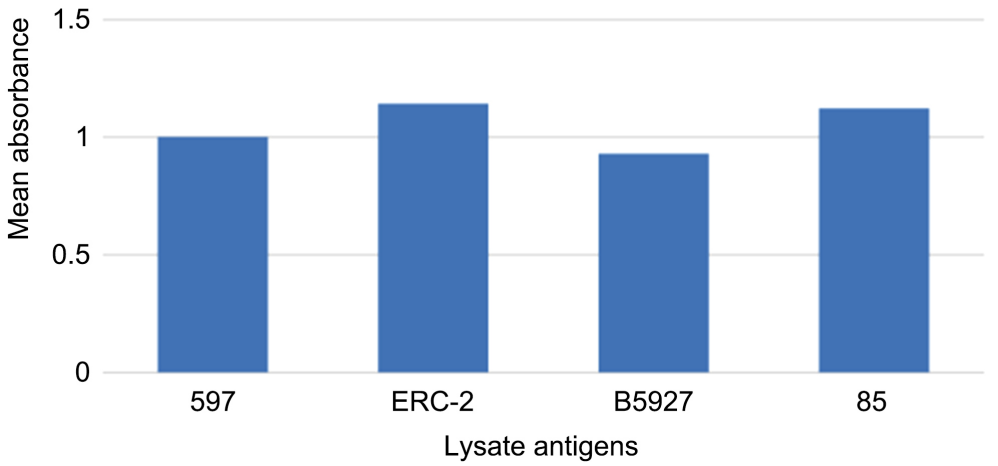

Figure 1. Mean antibody detection absorbance values $(450 \mathrm{~nm})$ obtained with the four antigens produced from Blastomyces isolates (597, human Wisconsin, ERC-2, dog Wisconsin, B5927, human Minnesota and 85, soil Georgia) in the STD ELISA. 


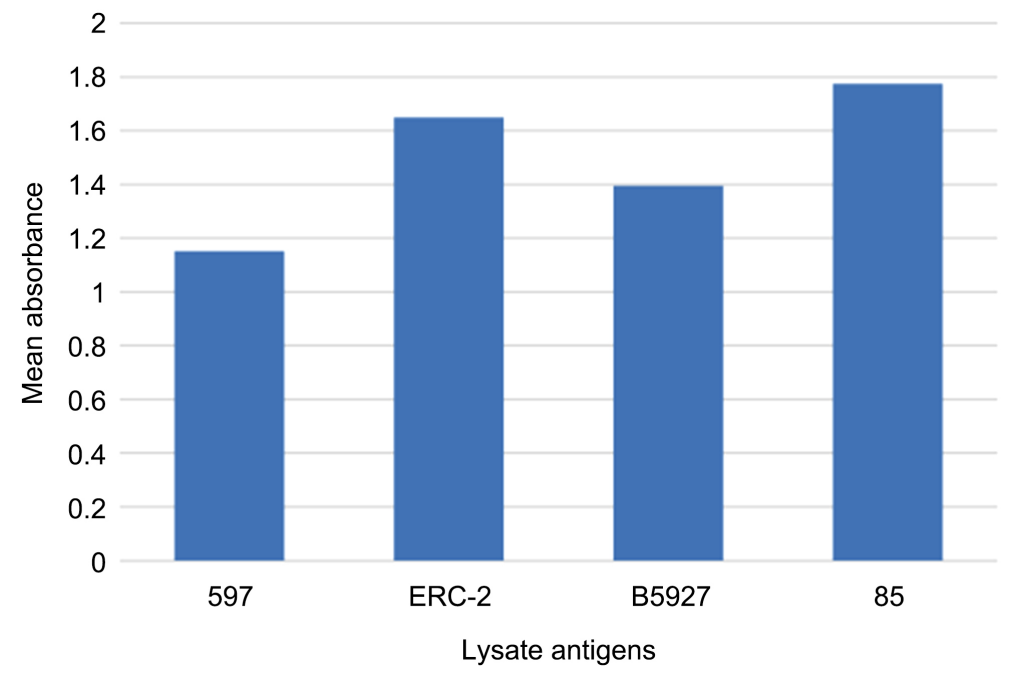

Figure 2. Mean antibody detection absorbance values. $(450 \mathrm{~nm})$ obtained with the four antigens produced from Blastomyces isolates (597, human Wisconsin, ERC-2, dog Wisconsin, B5927, human Minnesota and 85, soil Georgia) in the BS-A ELISA.

with Blastomyces yeast lysates or with whole killed yeast cells. The novel yeast lysate reagents were produced by methods that were previously used for the development of lysate antigens for the immunodiagnostic detection of coccidioidomycosis and histoplasmosis [23] [24] [25].

Our studies with these lysate antigens have provided encouraging results on the utility of the lysates in immunodiagnostic antibody detection assays. In the present study, we compared two ELISA methods (a standard indirect assay (STD) and a biotin-streptavidin (BS-A) assay using four lysate antigens for the detection of antibody in serum specimens from dogs with diagnosed blastomycosis.

The BS-A ELISA was the mostly sensitive of the two assays in this comparative evaluation. The BS-A may provide an earlier diagnosis of blastomycosis because of the increased sensitivity of the procedure due to the highly selective and stable binding of streptavidin to biotin. This method thus affords clinical laboratory personnel another option with regard to the diagnosis of blastomycosis in humans and animals.

With regard to antibody detection by the four Blastomyces lysate antigens the ERC-2 antigen, produced from a dog isolate from Wisconsin, and the 85 antigens, produced from a soil isolate from Georgia, exhibited the greatest antibody detection in both of the above immunoassays. Therefore one may conclude that with our lysate antigens and ELISA equipment/methods that either one of the yeast-phase lysate antigens would be reliable reagents for the detection of antibody in canine blastomycosis with either of the enzyme immunoassays. The results of this study are encouraging with regard to future research on the use of these assays and Blastomyces antigens, even though they were from completely different isolates of the organism, for the clinical laboratory diagnosis of canine blastomycosis. 


\section{Acknowledgements}

This research was supported by the Department of Biological Sciences, Idaho State University.

\section{Conflicts of Interest}

The authors declare no conflicts of interest regarding the publication of this paper.

\section{References}

[1] DiSalvo, A.F. (1998) Blastomycosis. In: Cox, F.E.G., Wakelin, D., Gillespie, S. and Despommier, D.D., Eds., 9th edition, Topley and Wilson's Microbiology and Microbial Infections, Arnold Publishers, London, UK, 337-355.

[2] Pfaller, M.A. and Diekema, D.J. (2010) Epidemiology of Invasive Mycoses in North America. Critical Reviews in Microbiology, 36, 1-53. https://doi.org/10.3109/10408410903241444

[3] Dalcin, D., Rotstein, A., Spinato, J., Escott, N., Kus, J.V. (2016) Blastomyces Gilchristii as Cause of Fatal Acute Respiratory Distress Syndrome. Emerging Infectious Diseases, 22, 306-308. https://doi.org/10.3201/eid2202.151183

[4] McBride, J.A., Gauthier, G.M. and Klein, B.S. (2017) Clinical Manifestations and Treatment of Blastomycosis. Clinics in Chest Medicine, 38, 435-449. https://doi.org/10.1016/j.ccm.2017.04.006

[5] Bradsher, R.W. (2014) The Endemic Mimic: Blastomycosis an Illness often Misdiagnosed. Transactions of the American Clinical and Climatological Association, 125, 188-203.

[6] Schwartz, I. and Kauffman, C. (2020) Blastomycosis. Seminars in Respiratory and Critical Care Medicine, 41, 31-41. https://doi.org/10.1055/s-0039-3400281

[7] Bariola, K.R. and Vyas, K.S. (2011) Pulmonary Blastomycosis. Seminars in Respiratory and Critical Care Medicine, 32, 745-753.

https://doi.org/10.1055/s-0031-1295722

[8] Saccente, M. and Woods, G.L. (2010) Clinical and Laboratory Update on Blastomycosis. Critical Microbiology Reviews, 23, 367-381. https://doi.org/10.1128/CMR.00056-09

[9] McKinnell, J.A. and Pappas, P.G. (2009) Blastomycosis: New Insights into Diagnosis, Prevention and Treatment. Clinics in Chest Medicine, 30, 227-239. https://doi.org/10.1016/j.ccm.2009.02.003

[10] Spector, D., Legendre, A.M., Wheat, J., et al. (2008) Antigen and Antibody Testing for the Diagnosis of Blastomycosis in Dogs. Journal of Veterinary Internal Medicine, 22, 839-843. https://doi.org/10.1111/j.1939-1676.2008.0107.x

[11] Vyas, K.S., Bariola, J.R. and Bradsher, R.W. (2008) Advances in the Serodiagnosis of Blastomycosis. Current Fungal Infection Reports, 2, Article No. 227. https://doi.org/10.1007/s12281-008-0033-z

[12] Bariola, J.R., Hage, C.A., Durkin, M.E., et al. (2011) Detection of Blastomyces Dermatitidis Antigen in Patients with Newly Diagnosed Blastomycosis. Diagnostic Microbiology and Infectious Disease, 69, 187-191.

https://doi.org/10.1016/j.diagmicrobio.2010.09.015

[13] Connolly, P., Hage, C.A., Bariola, J.R., et al. (2012) Blastomyces Dermatitidis Anti- 
gen Detection by Quantitative Enzyme Immunoassay. Clinical and Vaccine Immunology, 19, 53-56. https://doi.org/10.1128/CVI.05248-11

[14] Frost, H.M. and Novicki, T.J. (2016) Blastomyces Antigen Detection for Diagnosis and Management of Blastomycosis. Journal of Clinical Microbiology, 53, 3660-3662. https://doi.org/10.1128/JCM.02352-15

[15] Johnson, S.M. and Scalarone, G.M. (1989) Preparation and ELISA Evaluation of Blastomyces Dermatitidis Yeast Phase Lysate Antigens. Diagnostic Microbiology and Infectious Disease, 11, 81-86. https://doi.org/10.1016/0732-8893(88)90076-4

[16] Shurley, J.F., Legendre, A.M. and Scalarone, G.M. (2005) Blastomyes dermatitidis Antigen Detection in Urine Specimens from Dogs with Blastomycosis Using a Competitive Binding Inhibition ELISA. Mycopathologia, 160, 137-142. https://doi.org/10.1007/s11046-005-3153-9

[17] Andrae, D., Birch, K., Bybee, T., et al. (2012) Antigen Detection in Canine Blastomycosis: Comparison of Different Antibody-Antigen Combinations in Two Competitive ELISAs. Open Journal of Medical Microbiology, 2, 110-111. https://doi.org/10.4236/ojmm.2012.23016

[18] Searle, A. and Scalarone, G.M. (2012) Comparative Antibody Study for Antigen Detection in Urine Specimens for Diagnosis of Blastomycosis Using a Competitive Enzyme-Linked Immunosorbent Assay. Open Journal of Immunology, 2, 139-143. https://doi.org/10.4236/oji.2012.24017

[19] Chester, E.M., Axtell, R.C. and Scalarone, G.M. (2003) Blastomyces Dermatitidis Lysate Antigens: Antibody Detection in Serial Serum Specimens from Dogs with Blastomycosis. Mycopathologia, 156, 289-294. https://doi.org/10.1023/B:MYCO.0000003575.04692.2f

[20] Sestero, C.M. and Scalarone, G.M. (2006) Detection of IgG and IgM in Sera from Canines with Blastomycosis Using Eight Blastomyces dermatitidis Yeast Phase Lysate Antigens. Mycopathologia, 162, 33-37. https://doi.org/10.1007/s11046-006-0028-7

[21] Hammon, J., Kennell, B.C. and Scalarone, G.M. (2019) Blastomyces Dermatitidis Antibody and Antigen Detection: Comparison of Four Lysate Antigens and Antibodies Prepared from Human Isolates from a Blastomycosis Outbreak. Mycopathologia, 184, 661-666. https://doi.org/10.1007/s11046-019-00385-0

[22] Roy-Chowdhury, M., Muzzall, E., Baumgardner, D.J., Kennell, B.C., Esterbrook, A.C., Shurley, J.F. and Scalarone, G.M. (2019) Potential Clinical Utility of ERC-2 yeast Phase Lysate Antigen for Antibody Detection in Dogs with Blastomycosis. Medical Mycology. 57, 893-896. https://doi.org/10.1093/mmy/myy137

[23] Scalarone, G.M., Levine, H.B. and Chaparas, S.D. (1978) Delayed Hypersensitivity Responses of Experimental Animals to Histoplasmin from the Yeast and Mycelial Phases of Histoplasma capsulatum. Infection and Immunity, 21, 705-713. https://doi.org/10.1128/IAI.21.3.705-713.1978

[24] Levine, H.B., Scalarone, G.M. and Chaparas, S.D. (1979) Preparation of Fungal Antigens and Vaccines: Studies on Coccidioides Immitis and Histoplasma capsulatum. Contributions to Microbiology and Immunology, 3, 106-125.

[25] Levine, H.B., Scalarone, G.M., Campbell, G.D., et al. (1979) Histoplasmin-CYL, A Yeast Phase Reagent in Skin Test Studies in Humans. The American Review of Respiratory Disease, 119, 629-636. 